\title{
Thermo Luminescence Dating of Pottery Sample from Chukhur Gabala Archaeological Site in Gabala District of Azerbaijan
}

\author{
Mammadov S.G. ${ }^{1} \bowtie$ \\ Dadashov Z. Kh. ${ }^{2}$ (iD \\ Ahadov A. B. ${ }^{3}$ \\ Ahadova A.S." \\ Bayramov M.A. ${ }^{5}$ \\ Humbatov F.Y. ${ }^{6}$
}

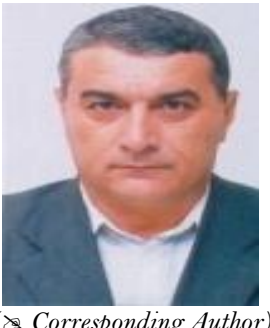

1.2,3,5,5.6Institute of Radiation Research Azerbaijan National Academy of Sciences, B. Vahabzade str., 9, Baku, Azerbaijan

:Email:mammadovsahib@yahoo.com

\begin{abstract}
The age of fragments of the ancient pottery sample from Chukhur Gabala archeological site in Gabala district of Azerbaijan has been estimated by employing Thermoluminescence dating (TL) method. The annual dose rate was obtained using $\gamma$-spectrometer with a hyper-pure germanium detector and it was $2.741 \pm 0.121 \mathrm{mGy} /$ year. The age of the sample was calculated by an additive dose method as $2230 \pm 510$ years which are in line with the stratigraphically estimated age of this area.
\end{abstract}

Keywords: Thermoluminescence dating, Pottery, Ceramics, Archeology, Chukhur-Gabala.

Citation | Mammadov S.G.; Dadashov Z. Kh.; Ahadov A. B.; Ahadova A.S.; Bayramov M.A.; Humbatov F.Y. (2018). Thermo Luminescence Dating of Pottery Sample from Chukhur Gabala Archaeological Site in Gabala District of Azerbaijan. International Review of Applied Sciences, 4(1): 1-5.

History:

Received: 9 July 2018

Revised: 13 August 2018

Accepted: 17 September 2018

Published: 26 October 2018

Licensed: This work is licensed under a Creative Commons

Attribution 3.0 License (cc)

Publisher:Asian Online Journal Publishing Group
Contribution/Acknowledgement: All authors contributed to the conception and design of the study.

Funding: This study received no specific financial support.

Competing Interests: The authors declare that they have no conflict of interests.

Transparency: The authors confirm that the manuscript is an honest Trcurate, and transparent account of the study was reported; that no vital study as planned have been explained.

Ethical: This study follows all ethical practices during writing.

\section{Contents}

1. Introduction

2. Experimental .2

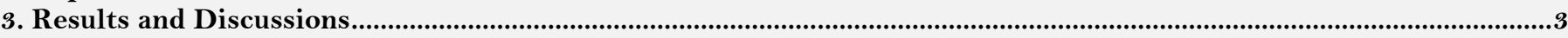

4. Conclusion

References. 


\section{Introduction}

In ancient times, Gabala was the capital of the ancient state of Caucasian Albania (from about III century BC V century AD). From June 18 to July 18, 2008, archaeological excavations were carried out near the village of Chukhur Gabala. During the excavations in the ancient city building remains and the foundation of a large barn, were found presumably, for food storage. Here, 33 lower parts of pits were placed in special rows from household jugs half buried in 42 square meters of land. Remnants of production character have been identified; samples of metal, ceramics, glass, bones create a detailed picture of the state of individual spheres of craft, as well as the level of lifestyle and culture of the urban population. Found during the excavation of coins, samples of pottery from faience, porcelain, and celadon tell of the intensive ties of Gabala XVI-XVII centuries with the cities of several countries of the world, including Iran and China. In the north-western part of the city for the first time, valuable finds were found in the form of a small door in the fortress wall, a door key, a network of multilateral ceramic water pipes.

The presented work aimed to increase the accuracy of dating real archeological monuments, namely, the fragments of the ancient pottery sample from Chukhur-Gabala archeological site in Gabala district of Azerbaijan by employing the TL method.

Luminescence of minerals upon heating (thermoluminescence), known since the XVII century and became a method of dating relatively recently. Thermoluminescence was suggested as a method for dating cultural materials and methods for applying the technique to archaeological materials were developed by Aitken in 1960's [1]. Since that time TL method became one of the most accurate and absolute method for dating pottery [2-4]. The essence of the method lies in the fact that the charged carriers (electrons and holes) formed in some crystals (luminophore) when irradiated are localized in the lattice at the capture centers, as a result of which accumulation of the absorbed energy occurs, which can then be released with additional excitation heating. In this case, a wave-like ignition is observed, followed by a decrease in the luminescence brightness associated with the release of electrons from the traps.

Pottery wares found in various archeological sites contain the inclusion of quartz and feldspar crystals $(<0.01 \%)$. Source of these crystals is clay- material that is used to make pottery wares. In some cases, they are also added to change the quality of the products. Emission from naturally occurring radioactive elements causes thermoluminescent centers to emerge and accumulate inside the crystals. The lifespan of thermoluminescent centers may vary from few days to few million years depending on the energy of these centers and their consistency may change depending on the temperature around. These centers anneal with rising temperatures and completely perish when reached 500 degrees Celsius. Needless to say, ceramic and porcelain wares, as well as ceramic water pipes, are made at temperatures above 500 degrees and therefore, the thermoluminescent activity of quartz grains is reduced to zero when produced. During later irradiation, thermoluminescent activity increases proportionally with the exposed radiation dosage. Using this property of quartz grains, it is possible to determine the age of ceramic and porcelain wares found during archaeological excavations. For this purpose, quartz crystals inside ceramic wares are obtained using special techniques and are exposed to additional radiation dosage. The historical dosage absorbed by ceramic ware is measured by plotting a linear graph of the dependent relationship between thermoluminescent intensity and radiation dosage and backward extrapolation. This dating technique is called quartz inclusion method.

\section{Experimental}

The pottery samples were collected from the depth of approximately $2.0 \mathrm{~m}$ with the geographical coordinates of $40^{\circ} 58^{\prime} 53^{\prime \prime} \mathrm{N}, 47^{\circ} 50^{\prime} 45^{\prime \prime} \mathrm{E}$ and about $780 \mathrm{~m}$ above sea-level. The original thickness of pottery shreds was 15 $\mathrm{mm}$. In order to preserve the content of water in the shreds, samples were places into plastic bags.

Quartz inclusion method is employed for the TL dating. The technique to prepare the sample is described below [5].

To eliminate the impact of $\beta$-emission on the dose absorbed in the past, $2 \mathrm{~mm}$ thick outer layer of the sample is extracted with special tools. Acquired fragments are first crumbled, and then gently crushed in an agate mortar. Non-magnetic part of fragments was separated through magnets. Too large crystal grains $(>200 \mu \mathrm{m})$ are separated using laboratory sieves. Crystals with diameters 90-150 $\mu \mathrm{ms}$ are used for thermoluminescent dating. To purify crystals from other minerals, first, they are soaked in $10 \%$ hydrochloric acid solution for a day and then kept in $30 \%$ hydrogen peroxide for 2 hours. To separate quartz grains from other crystals heavy liquids, like sodium polytungstate $(2,5-3 \mathrm{~g} / \mathrm{sm} 3)$ are used. To eliminate the effect of alpha particles radiated by uranium and thorium on dose absorbed by crystal grains, they are soaked in ( $1 \mathrm{~N}$ hydrofluoric acid) for 100 minutes [1]. At this stage minerals such as calcite and feldspar are discarded. For each sample thermoluminescence characteristics are measured around $1-14 \mathrm{mg}$ loads. The result shows that optimal weight for quartz grains like these is around 5-10 mg.

Quartz grains were divided into six equal parts and each aliquot was placed inside glass tubes (Suprasil) for laboratory irradiation. The samples were irradiated using a ${ }^{60} \mathrm{Co}$ source. A dose rate of the ${ }^{60} \mathrm{Co}$ source has been determined by Magnettech MiniscopeMS400 EPR Spectrometer using individually wrapped, barcode-labeled BioMax Alanine Dosimeter Films (developed by Eastman Kodak Company). In nature, the objects were irradiated at a very low dose rate conditions to compare with the laboratory irradiation. Dose mapping exercise has been conducted at three fixed location around 60Co source and dose rates were 0.194Gy/s, 0.0194Gy/s and 0.0098Gy/s consequently.

Harshaw TLD 3500 Manual Reader is used for the measuring TL characteristics of samples.

In order to determine the natural dose rate soil samples were collected in close proximity to the pottery sample. Uranium, Thorium and Potassium concentrations in soil were measured by gamma spectrometry Canberra GR4520 which has a low-level gamma spectrometry system with $15 \mathrm{~cm}$ lead shielding and high-resolution GeHP hyper-pure germanium detector, having $43.5 \%$ resolution efficiency for $661.6 \mathrm{keV}$. 
Dose rate and age calculation were conducted using the online DRAC version $1.2[6]^{1}$

\section{Results and Discussions}

Irradiated quartz grains exhibit a number of TL peaks when heated from room temperature to $500^{\circ} \mathrm{C}[2]$. Two peaks above $300^{\circ} \mathrm{C}$ were observed for quartz inclusions extracted from pottery. The peak observed at $375^{\circ} \mathrm{C}$ is considered preferable to compare to the peak on the lower shoulder of this peak, around $325^{\circ} \mathrm{C}$ [5]. Another peak which emerges under laboratory irradiation is around $110^{\circ} \mathrm{C}$ which it became the basis of the "pre-dose dating" method. It has demonstrated that the peak height could be used to monitor dose-dependent sensitivity changes which were observed after heating to $500^{\circ} \mathrm{C}$.

Fig. 1a illustrates the TL glow curve for quartz extracted from pottery sample measured at a heating rate of $20^{\circ} \mathrm{C}$. Dominant peak at $375^{\circ} \mathrm{C}$ visually distinguishable but peak at $325^{\circ} \mathrm{C}$ covered under the wide peak at $375^{\circ} \mathrm{C}$. The TL peak at $375^{\circ} \mathrm{C}$ has been used extensively for dating coastal dune sediments in Australia [7]. This emission has been suggested by McKeever [8] to be $\mathrm{AlO}_{4}$ acting as a hole trap in the quartz lattice. It was established [1] that this center is the most thermally stable and its lifetime is approximately $10^{8}$ years at $15^{\circ} \mathrm{C}$ with the depth of $1.66 \mathrm{eV}$. At the same time, it has been reported to saturate at relatively low doses and thus be thought not too useful for dating over $5 \times 10^{4}$ years. However, this peak has been used successfully in the dating of Australian beach ridges back to $5 \times 10^{5}$ years $[7]$ where natural dose rates are very low.

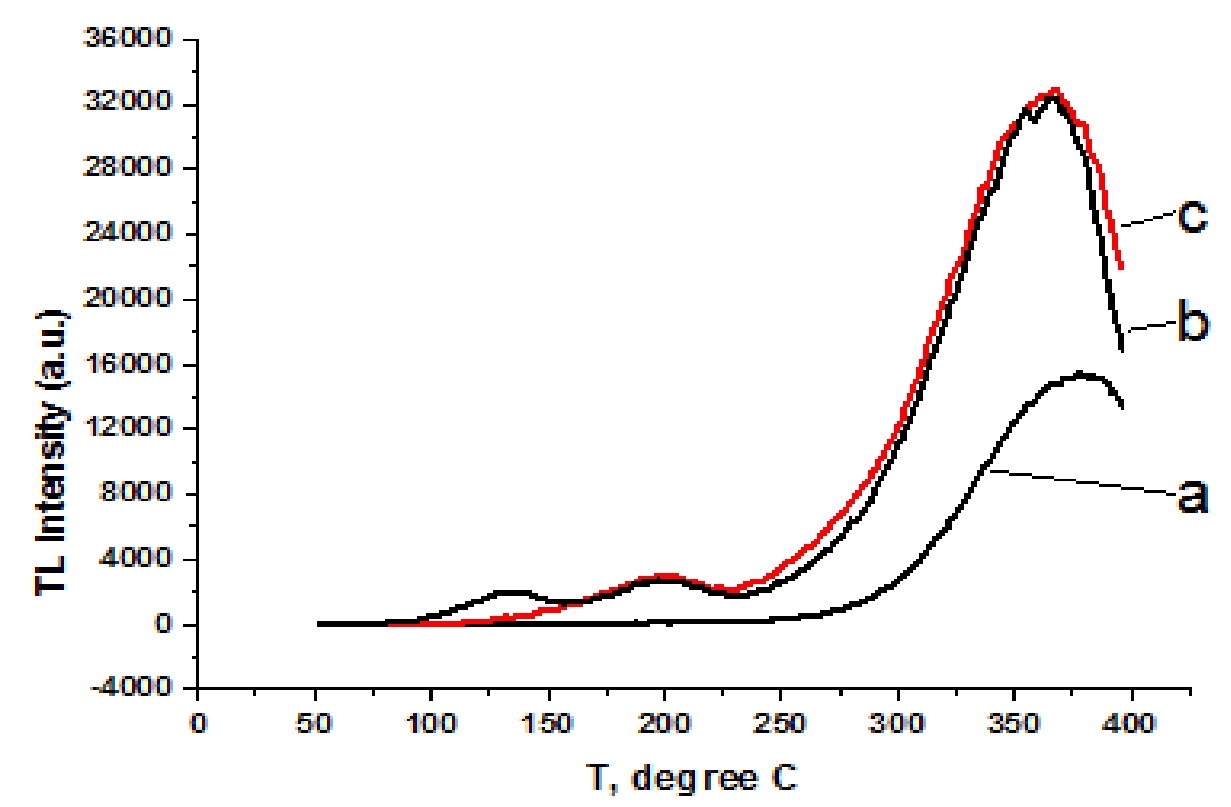

Figure-1.(a) TL glow-curve for quartz extracted from pottery sample measured at a heating rate $20^{\circ} \mathrm{C}$ showing the dominant peak at $375^{\circ} \mathrm{C}$; (b) TL glow-curve for quartz extracted from pottery sample additionally irradiated (24 Gy) by gamma-ray ${ }^{60} \mathrm{Co}$. TL glow-curve was measured in one hour after irradiation; (c) The same sample: TL glow-curve was measured in two days after irradiation.

Laboratory irradiation of the quartz grains extracted from the pottery sample leads to emerging two additional peaks. The glow-curve shown in Fig. $1 \mathrm{~b}$ is composed of a number of peaks and corresponds to different types of electron traps. Visually we observe three peaks at the temperature region of $120^{\circ} \mathrm{C}, 200^{\circ} \mathrm{C}$ and $375^{\circ} \mathrm{C}$ with the glow-curves about $50^{\circ} \mathrm{C}$ in width. The TL peak which appears around $120^{\circ} \mathrm{C}$ is known as $110^{\circ} \mathrm{C}$ peak. Kinetic parameters of the $110^{\circ} \mathrm{C}$ TL peak are given as $\mathrm{E}=0.98 \mathrm{eV}$ and lifetime is seven hours at $15^{\circ} \mathrm{C}[1]$. A peak in this region can be seen in all quartz, whether natural or artificial [9] provided that it has been irradiated for less than a few hours before measurements. As it was expected the peak at the $110^{\circ} \mathrm{C}$ region disappears after two days (Fig 1.c). Nevertheless, the peaks at $200^{\circ} \mathrm{C}$ and $375^{\circ} \mathrm{C}$ remain unaffected. The temperature region in which the peak appears directly relates to the energy level of the traps. The temperature required to release electrons for "deep traps" is higher than for "shallow traps". Consequently, the lifetime for electrons in "deep traps" is much longer than that of electrons in "shallow traps", which results in thermoluminescence below $200^{\circ} \mathrm{C}$ in the glow-curve. Therefore, traps that have accumulated electrons at the "deep traps" i.e. at $300-375^{\circ} \mathrm{C}$ are used for the dating purposes.

Fig 2 illustrates the dose dependence of the TL glow curve. Samples were irradiated with ${ }^{60}$ Co gamma source then TL glow-curves measured after two days.

\footnotetext{
1 (www.aber.ac.uk/alrl/drac)
} 


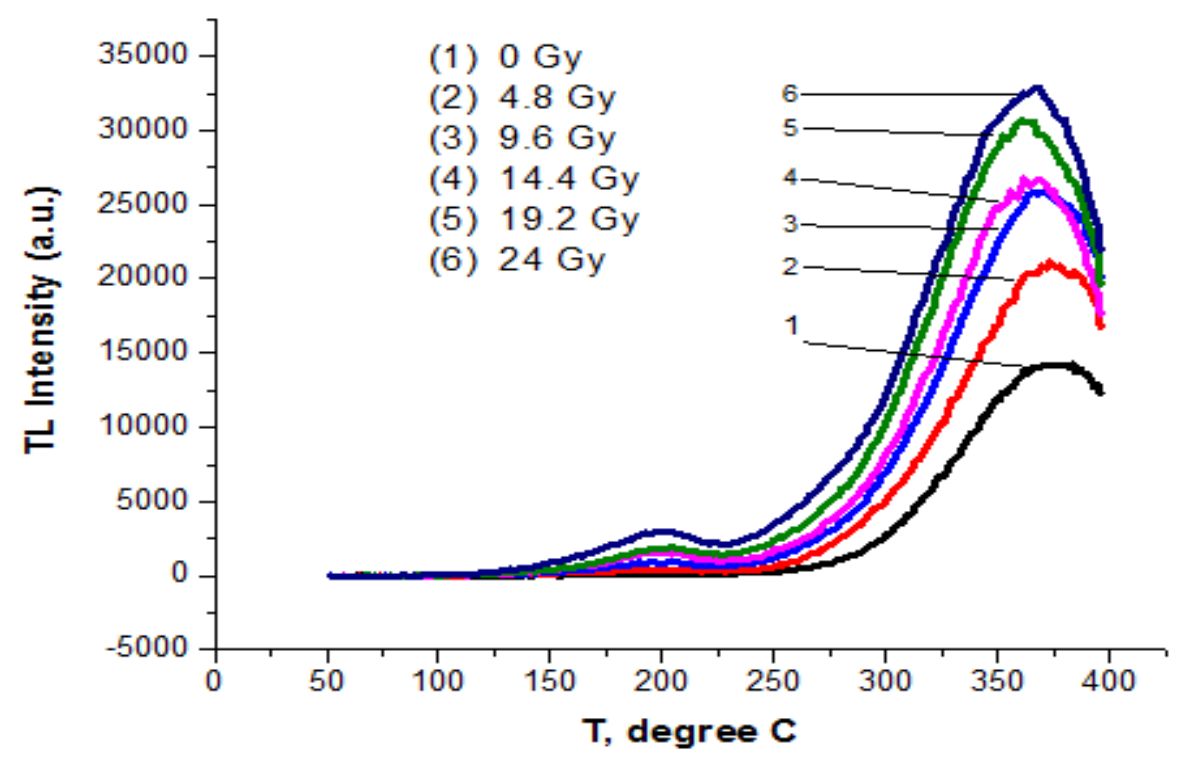

Figure-2. TL glow-curve of quartz samples at different additional laboratory doses. (1) The TL glow curve of quartz extracted from pottery sample without additional laboratory irradiation. The five aliquots of quartz were irradiated by gamma-ray ${ }^{60} \mathrm{Co}$ with additional laboratory doses 4.8 (2); 9.6 (3); 14.4 (4); 19.2 (5) and 24 Gy (6) respectively. Dose rate was $0.194 \mathrm{~Gy} / \mathrm{s}$. TL glow-curves were measured in two days after irradiation

Plotting the TL glow-curve intensity at $375^{\circ} \mathrm{C}$ against the dose adsorbed and backward extrapolation enables the estimation of historical dose equal to 6.12 1.36 Gy (Fig.3).

Soil sample collected from the close proximity of the pottery sample was air dried and kept in a closed environment for one month. The concentration of $\mathrm{U}, \mathrm{Th}$, and $\mathrm{K}$ are illustrated in Table 1.

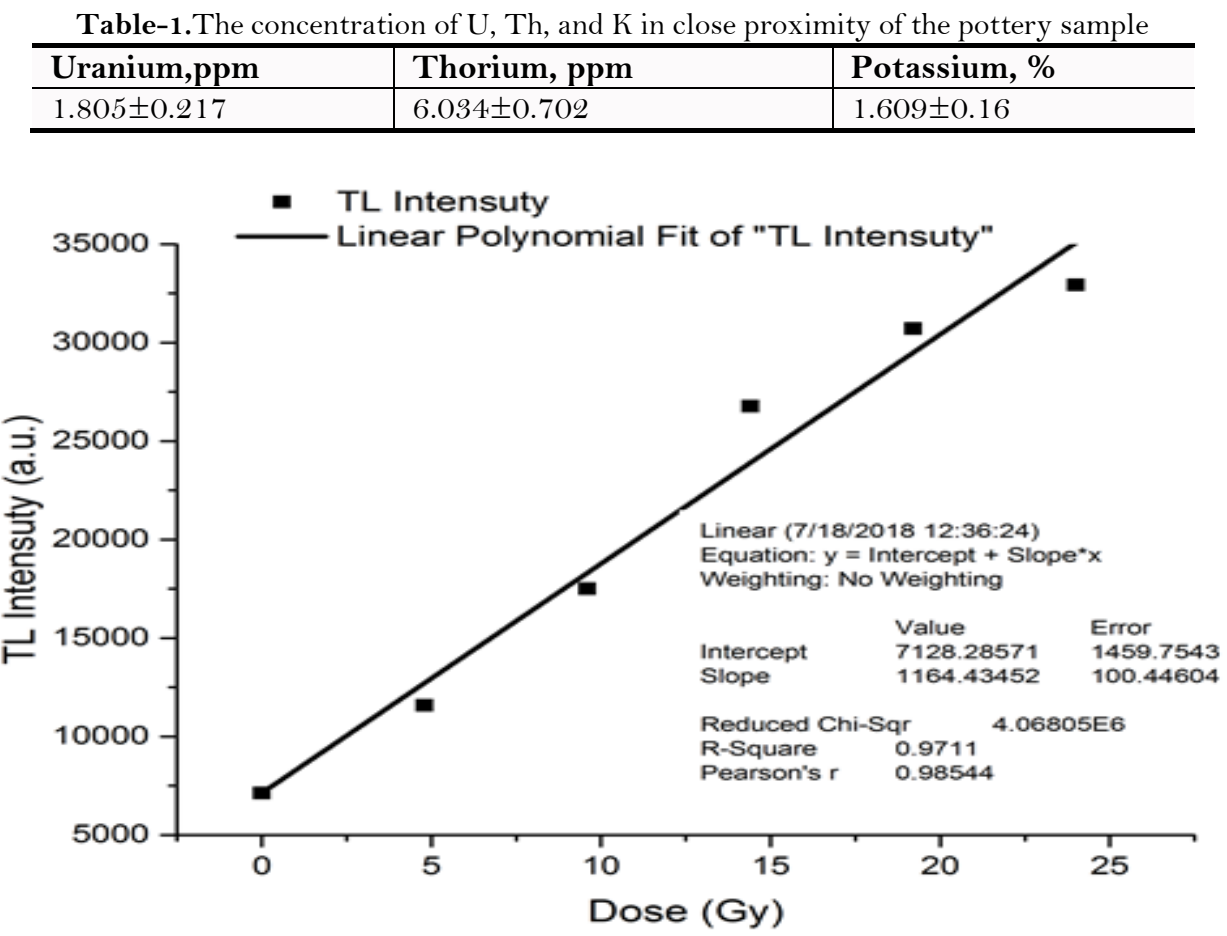

Figure-3. The dependency of TL intensity at $375^{\circ} \mathrm{C}$ peak from the additional laboratory dose. Linear fitting was performed with OriginPro v.9.1.

Dose rate and age calculation were conducted using the DRAC version 1.2 based on input figures as in Table 1 and output results are as follows:

Environmental dose rate: $2.741 \pm 0.121 \mathrm{~Gy} / \mathrm{ka}$ and;

Age of the sample: 2,230 \pm 510 years which are in line with the stratigraphically estimated age of this area.

\section{Conclusion}

The presented work was the first attempt aimed to increase the accuracy of dating real archeological monuments, namely, the fragments of the ancient pottery sample from Chukhur-Gabala archeological site in Gabala district of Azerbaijan by employing the TL method. The age of the sample was calculated by online dose rate and age calculator as $2,230 \pm 510$ years which are in line with the stratigraphically estimated age of this area.

\section{References}

M. J. Aitken, Thermo luminescence dating. Oxford: Academic Press, 1985.

K. Murthy, "Thermoluminescence and its applications: A review," Defect and Diffusion Forum, vol. 347, pp. 35-73, 2014.

S. Khasswneh, Z. Al-Muheisen, and R. Abd-Allah, "Thermo luminescence dating of pottery objects from tell Al-Husn, Northern Jordan," Mediterranean Archaeology and Archaeometry, vol. 11, pp. 41-49, 2011.

[4] M. Sekkina, M. El Fiki, S. Nossair, and N. Khalil, "Thermoluminescence archaeological dating of pottery in the Egyptian pyramids zone," Ceramics-Silikaty, vol. 47, pp. 94-99, 2003.

[5] S. Fleming, "Thermo luminescent dating: Refinement of the quartz inclusion method," Archaeometry, vol. 12, pp. 133-143, 1970.Available at: https://doi.org/10.1111/j.1475-4754.1970.tbooo16.x 
[6] J. A. Durcan, G. E. King, and G. A. Duller, "DRAC: Dose rate and age calculator for trapped charge dating," Quaternary Geochronology, vol. 28, pp. 54-61, 2015.Available at: https://doi.org/10.1016/j.quageo.2015.03.012.

C. V. Murray-Wallace, Quaternary history of the coorong coastal plain, Southern Australia: An archive of environmental and global sea-level changes: Springer, 2018.

[8] S. McKeever, "Mechanisms of thermo luminescence production: Some problems and a few answers?," International Journal of Radiation Applications and Instrumentation. Part D. Nuclear Tracks and Radiation Measurements, vol. 18, pp. 5-12, 1991.Available at: https://doi.org/10.1016/1359-0189(91)90085-v.

[9] S. Petrov and I. Bailiff, "Determination of trap depths associated with TL peaks in synthetic quartz (350-550 K)," Radiation Measurements, vol. 27, pp. 185-191, 1997.Available at: https://doi.org/10.1016/s1350-4487(96)00148-5. 